\title{
Epigenetic Changes at the Birc5 Promoter Induced by YM155 in Synovial Sarcoma
}

\author{
Aleksander Mika ${ }^{1}$ (D) Sarah E. Luelling ${ }^{2}$, Adriene Pavek ${ }^{2}$, Christopher Nartker ${ }^{2}$, \\ Alexandra L. Heyneman ${ }^{2}$, Kevin B. Jones ${ }^{1, *}$ and Jared J. Barrott ${ }^{1,2, * \mathbb{D}}$ \\ 1 Departments of Orthopedics and Oncological Sciences, Huntsman Cancer Institute, University of Utah \\ School of Medicine, Salt Lake City, UT 84112,USA; Aleksander_Mika@urmc.rochester.edu \\ 2 Department of Biomedical and Pharmaceutical Sciences, Idaho State University, Pocatello, ID 83209, USA; \\ luelsara@isu.edu (S.E.L.); paveadri@isu.edu (A.P.); nartchri@isu.edu (C.N.); heynalex@isu.edu (A.L.H.) \\ * Correspondence: kevin.jones@hci.utah.edu (K.B.J.); barrjare@isu.edu (J.J.B.); \\ Tel.: +1-801-585-0300 (K.B.J.); +1-208-282-4259 (J.J.B.)
}

Received: 12 February 2019; Accepted: 21 March 2019; Published: 24 March 2019

\begin{abstract}
YM155 is an anti-cancer therapy that has advanced into 11 different human clinical trials to treat various cancers. This apoptosis-inducing therapy indirectly affects the protein levels of survivin (gene: Birc5), but the molecular underpinnings of the mechanism remain largely unknown. Synovial sarcoma is a rare soft-tissue malignancy with high protein expression of survivin. We investigated whether YM155 would be a viable therapeutic option to treat synovial sarcoma. YM155 therapy was applied to human synovial sarcoma cell lines and to a genetically engineered mouse model of synovial sarcoma. We discovered that YM155 exhibited nanomolar potency against human synovial sarcoma cell lines and the treated mice with synovial sarcoma demonstrated a $50 \%$ reduction in tumor volume compared to control treated mice. We further investigated the mechanism of action of YM155 by looking at the change of lysine modifications of the histone tails that were within 250 base pairs of the Birc5 promoter. Using chromatin immunoprecipitation (ChIP)-qPCR, we discovered that the histone epigenetic marks of H3K27 for the Birc5 promoter changed upon YM155 treatment. H3K27me3 and H3K27ac increased, but the net result was decreased Birc5/survivin expression. Furthermore, the combination of molecular events resulted in caspase 3/7/8 upregulation and death of the sarcoma cells.
\end{abstract}

Keywords: survivin; Birc5; synovial sarcoma; YM155; epigenetics

\section{Introduction}

Synovial sarcoma is a soft-tissue malignancy with a predilection for adolescents and young adults. It is the fourth most common type of soft tissue sarcoma and accounts for $5-10 \%$ of all soft tissue sarcomas [1]. Synovial sarcoma is a well-established translocation-associated sarcoma and is defined by the presence of the $\mathrm{t}(\mathrm{X} ; 18)$ (p11.2; q11.2) translocation, involving the SS18 (formerly SYT) gene on chromosome 18 and one of several synovial sarcoma X (SSX) genes on chromosome $X$ (usually SSX1 or SSX2) [2]. Over 95\% of synovial sarcomas can be characterized by expression of the SS18-SSX gene and it is used as a routine diagnostic marker for this type of cancer [3]. The protein product of the translocation-generated fusion gene interferes with assembly of BAF (BRG/BRM and associated factors) complexes, leading to widespread alterations in chromatin remodeling and cell state reprogramming [4]. The main driving genetic event in this cancer is known, yet no means to target the fusion protein SS18-SSX directly exists. Patients diagnosed with synovial sarcoma share the lack of therapeutic options of many other translocation-positive sarcomas. 
Synovial sarcoma is generally considered a high-grade, aggressive sarcoma. However, progression can take several years as evidenced by an overall survival rate of $39 \%$ at 15 years [5]. The survival outcomes are much worse if the patient presents with metastatic disease at the time of diagnosis. At 5 years, the survival rate is $22 \%[5,6]$. Targeted therapeutic strategies are both lacking and greatly needed. Currently, the available drug regimens to treat synovial sarcoma consist of traditional cytotoxic chemotherapies with relatively high response rates, but very limited ultimate effectiveness $[7,8]$.

Survivin is a member of the inhibitor of apoptosis (IAP) gene family; its expression in tumors is associated with a more aggressive phenotype, shorter survival time, and decreased response to chemotherapy [9-11]. While it is clear that survivin restricts the execution of apoptosis, it has still not been fully resolved how survivin controls cell death [12]. In recent years, YM155 (sepantronium bromide) has been increasingly used as an anti-cancer agent due to its inhibitory effect on survivin. Despite the advancements of this drug in clinical trials, the mechanism whereby YM155 reduces survivin expression is also unknown. Reports differ on how YM155 might achieve indirect regulation of survivin, by epigenetically silencing Birc5 at the promoter $[13,14]$ or by altering posttranslational modifications that impact the stability of the survivin protein [15].

Our objective was to understand how YM155 induces synovial sarcoma cells to undergo apoptosis. In previous studies, YM155 has been found not only to affect the expression of survivin, but also the anti-apoptotic BCL2 family protein MCL1 in several tumor-derived cell lines [16]. These results have been reproduced for several other proteins including PI3-kinase, ERK, and STAT3 in PANC1 cells [17] and securin in glioblastoma [18]. Because YM155 is an effective pro-apoptotic compound, it has been difficult to determine if survivin expression is a direct effect of the drug on epigenetic regulation of the Birc5 promoter or if it is a secondary consequence of activating other pro-apoptotic pathways in synovial sarcoma.

\section{Experimental Section}

\subsection{Human and Mouse Expression Databases}

All clinical trial data for YM155 were obtained through queries using the clinicaltrials.gov website on November 6, 2018. BIRC5 gene expression in published cancer databases was established using the web-based data inquiry tool Metabolic gEne RApid Visualizer (MERAV) [19]. We restricted our search parameters to only those cancers represented in the YM155 human clinical trials. Mouse expression data were obtained by using the accession number GSE81476 from the NCBI GEO database.

\subsection{Mice}

Mouse experiments were conducted with the approval of the University of Utah's Institutional Animal Care Committee in accordance with legal and ethical standards established by the National Research Council and published in the Guide for the Care and Use of Laboratory Animals (protocol \# 14-01016). The previously described Rosa26-LSL-SS18-SSX2 mice [20] were maintained on a mixed strain background, C57BL/6 and SvJ. Mice were genotyped with the following primers: Rosa26-LSL-SS18-SSX2 (F flox-AAACCGCGAAGAGTTTGTCCTC, F wt-GTTATCAGTAA GGGAGCTGCAG-TGG, R-GGCGGATCACAAGCAATAATAACC). TATCre was dosed by $10 \mu \mathrm{L}$ intramuscular injections at $50 \mu \mathrm{M}$ at 1 month of age.

\subsection{Cell Lines}

The human SYO-1, Yamato, and HS-SY-II cell lines were received from Torsten Nielsen at the University of British Columbia. The MoJo cell line was developed as previously described from a consented patient's synovial sarcoma [21]. Each was maintained in Dulbecco's modified Eagle medium (DMEM) with 10\% fetal bovine serum (FBS) and tested for mycoplasma using MycoAlert Plus (Lonza, Walkersville, MD, USA) every 6 months. 


\subsection{YM155 Mouse Treatments}

Mice had tumors initiated at 1 month of age. Tumors developed for the next 6 months allowing tumor volumes to reach $500-1000 \mathrm{~mm}^{3}$. Mice were then subjected to daily intraperitoneal injections of $20 \mathrm{mg} / \mathrm{kg}$ of YM155 for 11 days. One mouse with bilateral tumors was censored at day 7. Tumors were measured using digital calipers and volumes were calculated using the equation $\left(L * W^{2}\right) / 2$. A small portion of the tumor was fixed in $4 \%$ paraformaldehyde overnight and then embedded in paraffin. The rest of the tumor was flash frozen in liquid nitrogen and stored at $-80^{\circ} \mathrm{C}$ until further use.

\subsection{MTT Viability Assay and caspase 3/7 and caspase 8 Enzymatic Activity}

Cells were seeded in a 96-well tissue culture dish at $1 \times 10^{4}$ cells per well. Twenty-four hours after seeding, serial dilutions of YM155 were applied so that the final concentration ranged from $10 \mu \mathrm{M}$ to $1 \mathrm{nM}$. Between 24 to $48 \mathrm{~h}$, MTT at $5 \mathrm{mg} / \mathrm{mL}$ was applied, and the cells were allowed to incubate at $37{ }^{\circ} \mathrm{C}$ and $5 \% \mathrm{CO}_{2}$ for $2.5 \mathrm{~h}$. Formazan crystals were resolubilized in $10 \% \mathrm{SDS}$ and $0.01 \mathrm{M} \mathrm{HCl}$. Absorbance was measured at $570 \mathrm{~nm}$ and normalized to $650 \mathrm{~nm}$. Caspase activity was measured using the Caspase-Glo $3 / 7$ and Caspase-Glo 8 (Promega, G8090, and G8200) assay systems. The manufacturer's instructions were followed for a 96 -well plate assay.

\subsection{Immunohistochemistry and Immunoblotting}

Paraffin-embedded tissues were stained by immunohistochemistry by rehydrating slides through a citrosolv and ethanol dilution wash. Antigen-retrieval was performed in $10 \mathrm{mM}$ sodium citrate ( $\mathrm{pH}$ 6.0). Sections were immunostained with the primary antibody anti-Survivin (Abcam, ab182132, 1:500) followed by horseradish peroxidase detection methods and counterstained with hematoxylin. Images were taken with a Leica DM6B Brightfield Microscope.

Protein was isolated from cells or tissues by incubating in a mild lysis buffer $(10 \mathrm{mM}$ Tris- $\mathrm{HCl} \mathrm{pH}$ $8.1,10 \mathrm{mM} \mathrm{NaCl}, 0.5 \% \mathrm{NP}-40$, and proteinase inhibitors). The fractions were clarified at $14,000 \mathrm{rpm}$ for $10 \mathrm{~min}$ before loading 25-50 $\mathrm{\mu g}$ / sample for gel electrophoresis and transfer to PVDF membrane. Western blots were probed with the following primary antibodies: anti-Survivin (Cell Signaling Technology, 2808, 1:1000), anti-NFKB/p65 (Cell Signaling Technology, 8242, 1:800) anti-GAPDH (Proteintech, 10494-1-AP, 1:1000). The immunoblots were probed secondarily with goat anti-rabbit antibodies conjugated with horse radish peroxidase and bands were detected using Bio-Rad Gel Doc MP imaging station.

\section{7. qPCR Birc5 Detection}

Tumor DNA was harvested using DNeasy tissue and blood kit (Qiagen, 69504, Germantown, MD, USA). Quantitative PCR used the PerfeCTa SYBR Green FastMix (Quanta Biosciences, 95072-250, Gaithersburg, MD, USA) and a CFX Connect (Bio-Rad Laboratories, Hercules, CA, USA) for detection using the following primer sequences: mouse Birc5 sense-ATCGCCACCTTCAAGAACTG and anti-sense-GGCCAAATCAGGCTCGTTCT; mouse Gapdh sense-TGTCAGCAATGCATCCTGCA and anti-sense-CCGTTCAGCTCTGGGATGAC; human BIRC5 sense-GCCTGGCAGCCCTTTCTCAA and anti-sense-TCCCAGCCTTCCAGCTCCTT; human GAPDH sense-GTCAAGGCTGAGAACGGGAA and anti-sense-GCCTTCTCCATGGTGGTGAA.

\subsection{Chromatin Immunoprecipitation-Quantitative PCR}

Mouse tumors were pulverized in a Covaris tissueTUBE attached to a Covaris glass tube $(13 \times 65 \mathrm{~mm})$ using a hammer and an aluminum block on dry ice. Samples were intermittently placed in liquid nitrogen to maintain molecular interactions. The powderized tissue was resuspended in PBS + protease inhibitors (Sigma, 11836153001, St. Louis, MO, USA) and fixed in 1\% formaldehyde for $10 \mathrm{~min}$ at room temperature. The cross linking was quenched by adding $125 \mathrm{mM}$ glycine. Samples were washed three times using cold PBS and cold centrifugation at $1000 \times g$ for 5 min. Similarly, cells 
can be fixed in $1 \%$ formaldehyde and washed while cells are still adherent to the bottom of the tissue culture dish. Cells in both cases were lysed using cold Farnham cell lysis buffer (5mM PIPES pH $8.0,85 \mathrm{mM} \mathrm{KCl}, 0.5 \% \mathrm{NP}-40$ ) with protease inhibitors by incubating on ice for $10 \mathrm{~min}$. Cells were collected and dounced with a glass tube and rod 20 times with a loose rod and 10 times with a tight rod. Samples were filtered through $70 \mu \mathrm{m}$ filter and centrifuged at $1000 \times g$ for $10 \mathrm{~min}$. The supernatant was removed and $1 \mathrm{~mL}$ of RIPA lysis buffer (1\% NP- $40,0.5 \%$ Na deoxycholate, $0.1 \%$ SDS $/ \mathrm{PBS}$ ) was added for every $300 \mathrm{mg}$ of tissue or $1 \times 10^{7}$ cells and incubated on ice for $10 \mathrm{~min}$. Sonication proceeded in the following manner: $1 \mathrm{~mL}$ aliquots were sonicated with a $30 \mathrm{~s}$ on and $30 \mathrm{~s}$ off cycle for 8 cycles totaling $4 \mathrm{~min}$ of sonication time. Sonicated samples were centrifuged at $1400 \mathrm{rpm}$ for $5 \mathrm{~min}$ and the supernatant was kept for chromatin immunoprecipitation.

Dynabeads (Invitrogen, 11204D, Carlsbad, CA, USA) were washed in $0.5 \mathrm{mg} / \mathrm{mL}$ BSA/PBS three times on a magnet. Sonicated samples were precleared with $30 \mu \mathrm{L}$ of beads for $1 \mathrm{~h}$ at $4{ }^{\circ} \mathrm{C}$. After preclearing, $50 \mu \mathrm{L}$ of the sample was set aside as the input DNA. Supernatants were transferred to a new tube and $5 \mu \mathrm{g}$ of primary antibodies were added and incubated overnight at $4{ }^{\circ} \mathrm{C}$. The following antibodies were used for immunoprecipitation. Anti-H3K27me3 (Rockland, 600-401-I84), anti-H3K27ac (Rockland, 600-401-K00), anti-H3K4me1 (Rockland, 600-401-I61), and anti-NFkB/p65 (Cell Signaling Technology, 8242). Samples were centrifuged at 10,000 $\times g$ for $5 \mathrm{~min}$ and then combined with $100 \mu \mathrm{L}$ of washed Dynabeads to be incubated for $4 \mathrm{~h}$ at $4{ }^{\circ} \mathrm{C}$. Unbound sample was washed off six times with RIPA buffer, twice with $\mathrm{LiCl}$ buffer, and once with TE. $100 \mu \mathrm{L}$ of elution buffer ( $1 \%$ SDS, $0.1 \mathrm{M} \mathrm{NaHCO}$, RNaseA) was added and incubated for $0.5 \mathrm{~h}$ at $37^{\circ} \mathrm{C}$ followed by the addition of proteinase $\mathrm{K}$ and incubation at $37^{\circ} \mathrm{C}$ for another $2.5 \mathrm{~h}$. Samples were subsequently incubated at $65^{\circ} \mathrm{C}$ for $9 \mathrm{~h}$. DNA was purified using a DNA ChIP clean up and concentrator (Zymo, D5205, Irvine, CA, USA) following the manufacturer's recommendations. Samples were diluted to $0.5 \mathrm{ng} / \mu \mathrm{L}$ and $\mathrm{qPCR}$ reactions were set up and run using the PerfeCTa SYBR Green FastMix and a CFX Connect for detection using the following primer sequences: human BIRC5 promoter sense-GGGTGGATCACAAGGTCAGG and anti-sense-CACCACGCCTGGCTAATTTT; mouse Birc5 promoter sense-CTGGCCAAATCCTGCAAACC and anti-sense-CTTTAAAGCATGTCCGCTGCA. The parameters for thermal cycling were $95^{\circ} \mathrm{C}$ for $15 \mathrm{~s}$ for initiation followed by 40 cycles at $95^{\circ} \mathrm{C}$ for $15 \mathrm{~s}$ followed by $60^{\circ} \mathrm{C}$ for $60 \mathrm{~s}$.

\subsection{Statistical Methods}

The control mice group with tumor was compared to the YM155 treated tumor group in a single factor ANOVA statistical test. For most comparisons between control and YM155 treated synovial sarcomas, Student's t-tests were performed.

\section{Results}

\subsection{Clinical Trials Data on YM155}

The clincialtrials.gov website was searched to identify all previous clinical trials involving the use of YM155. Eleven registered phase 1 and 2 trials were identified. 405 patients with various forms of cancer were treated with YM155, with the earliest studies ending in 2007 and the most recent ending in 2015 (Table 1). Most of the clinical trials have not published or released their data. In the case of two clinical trials that were published the data supported not continuing the clinical trials due to serious adverse events or no statistical improvement over the standard of care [22,23]. While YM155 is associated with adverse events at doses above $4.8 \mathrm{mg} / \mathrm{m}^{2} /$ day [24], proper combination therapies might be able to achieve efficacy and avoid toxicity-related events. 
Table 1. Summary of clinical trials using YM155 in cancer.

\begin{tabular}{lcccc}
\hline Study Identifier & $\begin{array}{c}\text { Number of } \\
\text { Patients }\end{array}$ & Phase & Disease & Date Ended \\
\hline NCT01023386 & 6 & phase 1 & cancer & 2010 \\
NCT00818480 & 10 & phase 2 & $\begin{array}{l}\text { prostate cancer, melanoma, } \\
\text { non-Hodgkin's Lymphoma }\end{array}$ & 2012 \\
NCT01007292 & 43 & phase 2 & non-Hodgkin's Lymphoma & 2015 \\
NCT01009775 & 64 & phase 2 & melanoma & 2012 \\
NCT01038804 & 101 & phase 2 & breast cancer & 2013 \\
NCT00498914 & 41 & phase 2 & lymphoma & 2009 \\
NCT01100931 & 42 & phase 1/2 & NSCLC 2, solid tumors & 2015 \\
NCT00514267 & 32 & phase 1/2 & prostate cancer, tumors & 2015 \\
NCT00281541 & 29 & phase 2 & melanoma & 2012 \\
NCT00328588 & 37 & phase 2 & NSCLC 2 & 2008 \\
NCT00257478 & NA ${ }^{1}$ & phase 2 & prostate cancer & 2007 \\
\hline
\end{tabular}

\subsection{Synovial Sarcoma Exhibits Similar BIRC5 Expression Levels to Other Cancers}

Using the web-based data inquiry tool Metabolic gEne RApid Visualizer (MERAV) [19], we searched human cancers that have been previously targeted in clinical trials using YM155 and compared the BIRC5 gene expression levels in these cancers to synovial sarcoma (Figure 1a,b). We observed that synovial sarcoma was not dissimilar from other cancers in terms of their BIRC5 gene expression nor in the ratio of gene expression found in the cancer compared to the corresponding normal tissue. This prompted us to pursue YM155 studies in synovial sarcoma.

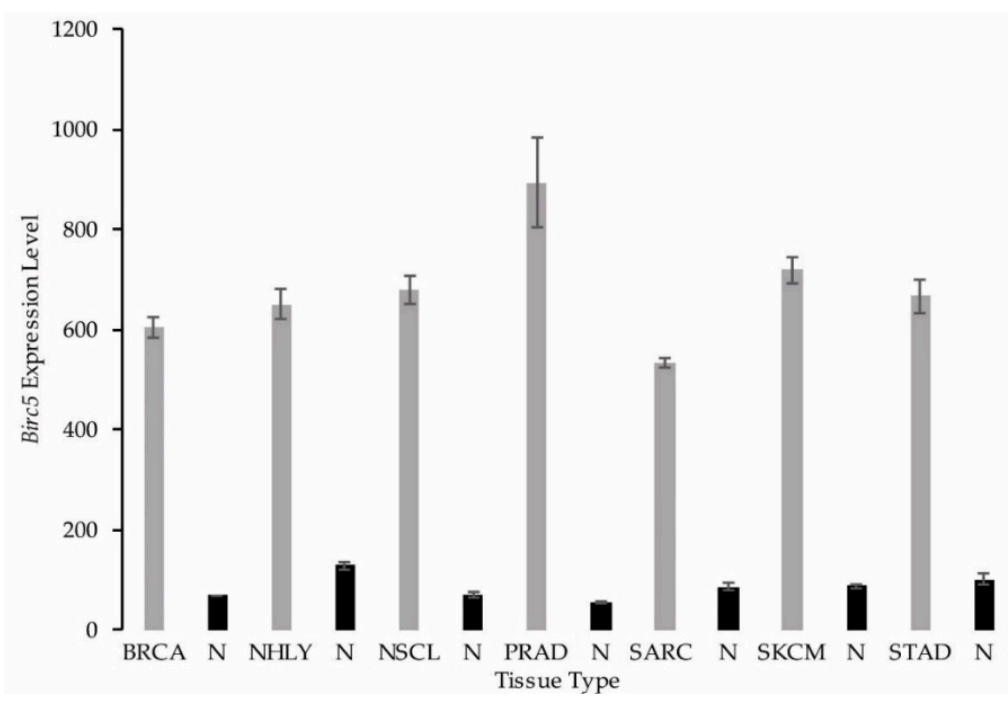

(a)

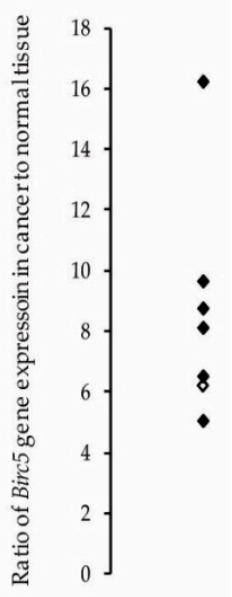

(b)

Figure 1. BIRC5 gene expression in various cancer types. (a) Mean BIRC5 gene expression in cancers (grey bars) and the corresponding mean in normal tissue $(\mathrm{N}$; black bars). BRCA $=$ breast invasive carcinoma $(n=190)$, NHLY = non-Hodgkin's Lymphoma $(n=40)$, NSCL $=$ non-small cell lung cancer $(n=65)$, PRAD = prostate adenocarcinoma $(n=15)$, SARC $=$ synovial sarcoma $(n=3)$, SKCM = skin cutaneous melanoma $(n=156)$, STAD = stomach adenocarcinoma $(n=38)$; (b) Ratio of BIRC5 gene expression in cancers to normal tissue. Synovial sarcoma is the open diamond. Means are represented \pm SEM. 


\subsection{Birc5/Survivin Expression in a Mouse Model of Synovial Sarcoma}

We have developed a genetically engineered mouse model of synovial sarcoma with a high correspondence to the pathophysiology of the human synovial sarcoma, including spontaneous generation of pulmonary metastases [20]. We evaluated our mouse models of synovial sarcoma for Birc5 gene expression and found increased levels of transcript in the sarcoma tissue compared to normal skeletal muscle $\left(p=1.4 \times 10^{-4}\right)$. The ratio between Birc5 expression in the mouse synovial sarcomas compared to the normal tissue was 7.0 and was very comparable to the 6-fold increase seen in the human comparison (Figure 2a). Immunohistochemical analysis of survivin demonstrated that the protein is expressed in these mice (Figure $2 b$ ). There was no difference in expression between the metastatic model and the non-metastatic model of synovial sarcoma. Mean FPKM (Fragments Per Kilobase of transcript per Million mapped reads) \pm SEM for Birc5 was $5.8 \pm 1.3$ and $6.4 \pm 2.4$, respectively $(p=0.82$ ) (Figure 2c). These means in synovial sarcoma represent a $\log 2$ ratio of 5.3 or about a 40-fold increase in Birc5 expression over mouse skeletal muscle. These values indicate that Birc5 expression is not unique to the metastatic disease, but can be targeted equally in metastatic and non-metastatic synovial sarcomas.

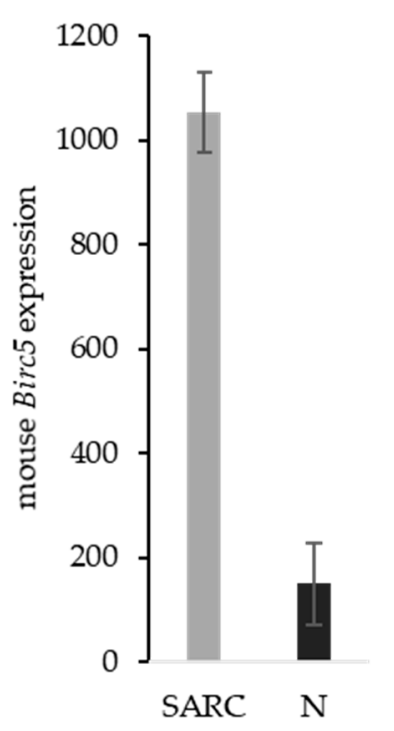

(a)

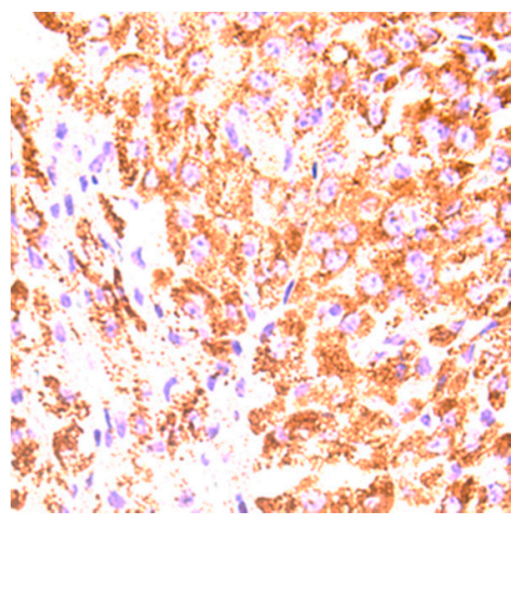

(b)

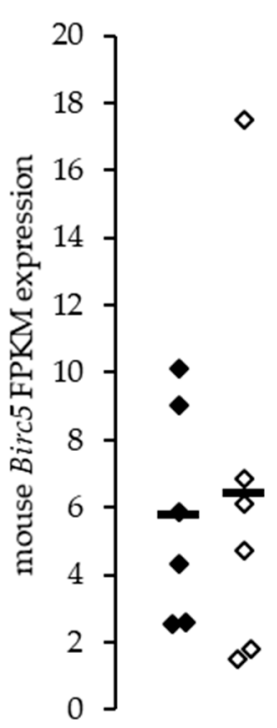

(c)

Figure 2. Birc5/Survivin expression in mouse models of synovial sarcoma. (a) Mean microarray expression for Birc5 in mouse synovial sarcoma $(n=5)$ and mouse skeletal muscle $(n=4)$. (b) Survivin protein expression in murine synovial sarcoma. Scale bar $=50 \mu \mathrm{m}$. (c) Birc5 gene expression in murine non-metastatic $(\diamond)$ synovial sarcoma and metastatic $(\diamond)$ synovial sarcoma. Bars represent means. Dashed red line represents normal skeletal muscle mean.

\subsubsection{YM155 Inhibition of Human Synovial Sarcoma Cells in Vitro}

Three established human cell lines for synovial sarcoma were used to determine the $\mathrm{EC}_{50}$ of the inhibitor YM155 in vitro. After $48 \mathrm{~h}$ exposure to serial dilutions of YM155, similar nanomolar $\mathrm{EC}_{50}$ values were observed for all three cell lines (Figure 3). The Yamato cell line was the most responsive and also exhibited the most survivin protein level (Figure A1). This submicromolar potency prompted further investigation of YM155 in our mouse model of synovial sarcoma. 


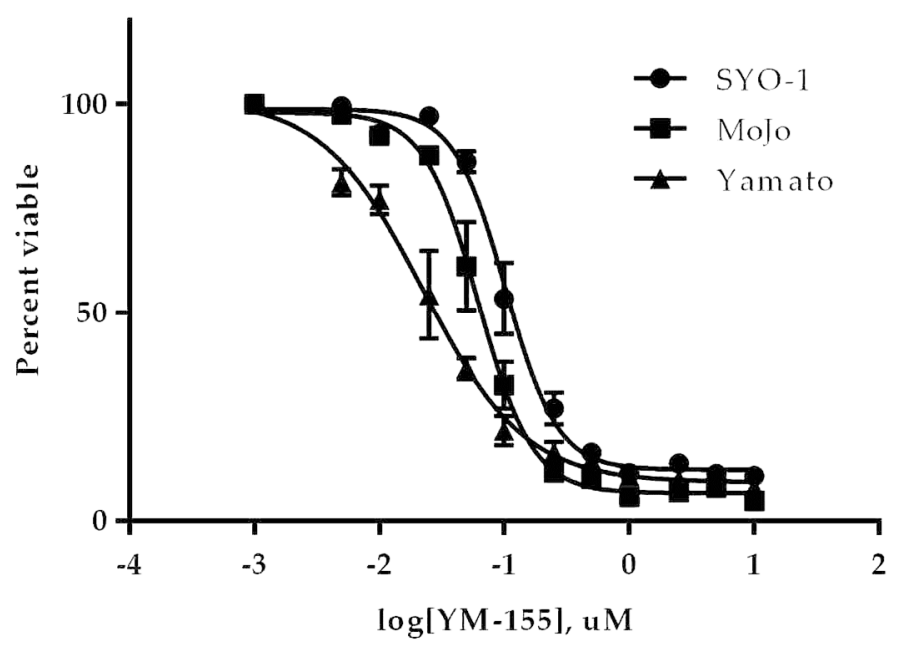

Figure 3. YM155 efficacy against human synovial sarcoma cell lines. Cells were treated for $48 \mathrm{~h}$ with various concentrations of YM155 and then assayed for the conversion of MTT to formazan and correlated to cell viability. YM155 showed the greatest potency in Yamato with an $\mathrm{EC}_{50}$ of $22 \mathrm{nM}$ followed by Mojo and SYO-1 with $\mathrm{EC}_{50} \mathrm{~s}$ of $62 \mathrm{nM}$ and $103 \mathrm{nM}$, respectively.

\subsubsection{YM155 Inhibition of Murine Synovial Sarcomas in Vivo}

Synovial sarcomas expressing the gene Rosa26-LSL-SS18-SSX2 were induced with a localized injection of the protein TATCre in the anterior tibialis of the left hindlimb, right hindlimb, or both. Seven mice, accounting for 10 synovial sarcomas, were treated with $20 \mathrm{mg} / \mathrm{kg}$ of YM155 for 11 days. Four mice, accounting for 4 tumors, were treated with the vehicle control. The tumor growth was plotted against time and the mean growth rate of the control treated sarcomas exhibited a 1.78-fold increase over 11 days, whereas the YM155 treated tumors saw a $17 \%$ decrease during the same time period (Figure $4 a, b)$. A single factor ANOVA revealed a statistically significant difference between the groups $(p=0.028)$. While one mouse was censored on day 7in the treatment group, there was no detectable weight loss in any of the YM155 treated mice (Figure A2), including the censored mouse that had such a dramatic response to the therapy before dying.

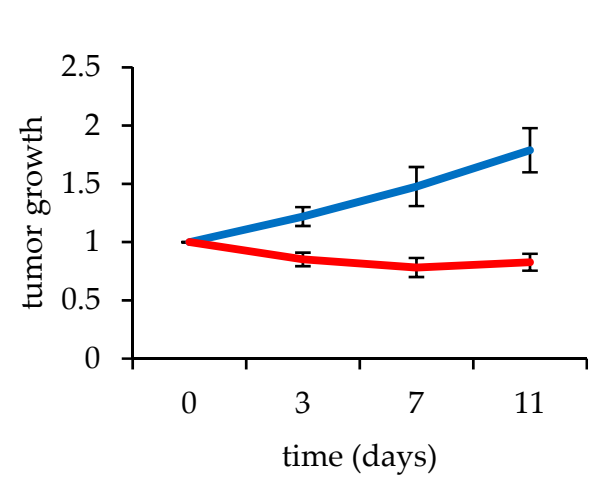

(a)

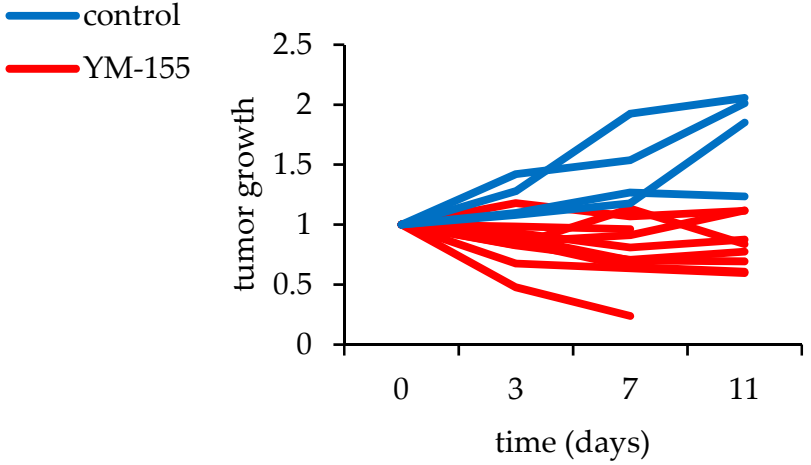

(b)

Figure 4. YM155 treatments of a mouse model of synovial sarcoma. (a) Mean values of tumor growth for mice treated with YM155 (red) and control treated (blue), bars represent the SEM; (b) Individual tumor growths represented for the 11 treated synovial sarcomas and the 4 control synovial sarcomas.

\subsubsection{The Effects of YM155 Inhibition in Murine Synovial Sarcoma on Birc5/Survivin}

The most notable cellular response to YM155 therapy in most settings is characterized by decreased levels of survivin protein. We therefore measured survivin levels in our mice that were treated with 
YM155. Protein was extracted from sarcomas involved in the animal study of YM155. A striking decrease of survivin was measured after immunoblotting in the YM155 treated sarcomas. Despite the large variation in the control treated samples, the comparison between control and YM155 treated synovial sarcomas was significant ( $p=0.034$, Student's $t$-test) (Figure 5a,b).

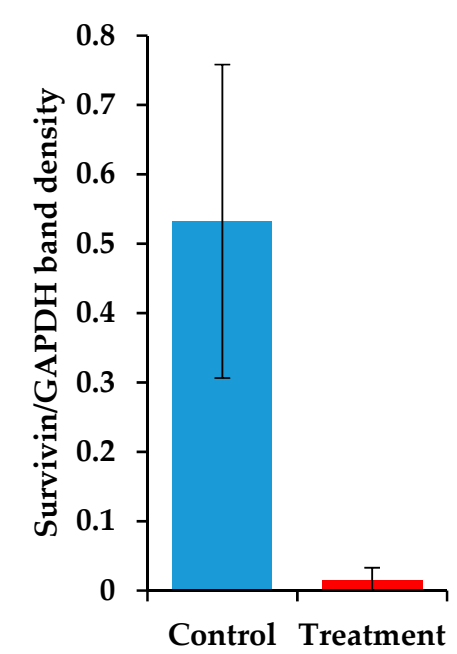

(a)

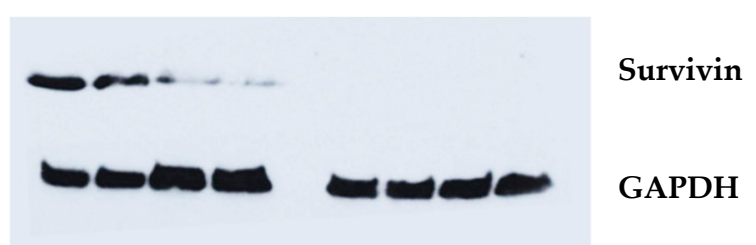

Control YM155 treated

Figure 5. YM155 decreases survivin in mouse synovial sarcomas. (a) Survivin expression was immunoblotted and band density was measured. Survivin expression was normalized to GAPDH protein levels, bars represent the SEM, $n=4$; (b) Immunoblots of survivin (top) and GAPDH (bottom) in control and YM155 treated mice after 11 days.

\subsection{Establishing an in Vitro Model to Determine the Mechanism of Action of YM155}

While it is noteworthy to discover another potential indication for the use of YM155 to treat cancers, we sought to understand better how YM155 exerts its negative effects on Birc5/Survivin expression. To determine the mechanism of action of YM155, we used another human synovial sarcoma cell line HS-SY-II. This cell line demonstrated a decreased sensitivity to YM155, albeit in a $24 \mathrm{~h}$ viability assay $\left(\mathrm{EC}_{50}=2.64 \pm 0.14 \mu \mathrm{M}\right)$ compared to previously assayed cell lines over $48 \mathrm{~h}$. However, during this shortened treatment duration, we observed decreases in Birc5 expression corresponding increases in apoptosis (Figure 6a-c). Congruently, levels of caspase $3 / 7$ and caspase 8 activity increased with higher concentrations of YM155 as detected by Caspase-Glo bioluminescent assays after $24 \mathrm{~h}$ incubation with YM155 (Figure 6b). Levels of BIRC5 were measured by semi-quantitative PCR and transcript levels were normalized between control and YM155 treated samples using GAPDH mRNA expression. We observed a 39.5\% reduction in normalized BIRC5 expression in YM155 treated synovial sarcomas $(p=0.0006)$ (Figure 6c). HS-SY-II cells also proved to be the most effective synovial sarcoma cell line in terms of sample preparation and DNA fragmentation for chromatin immunoprecipitation assays. 


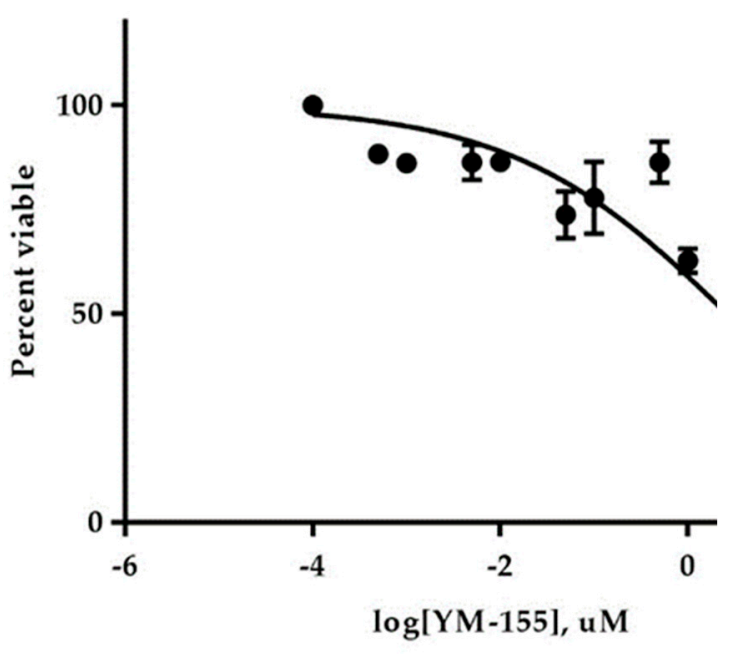

(a)

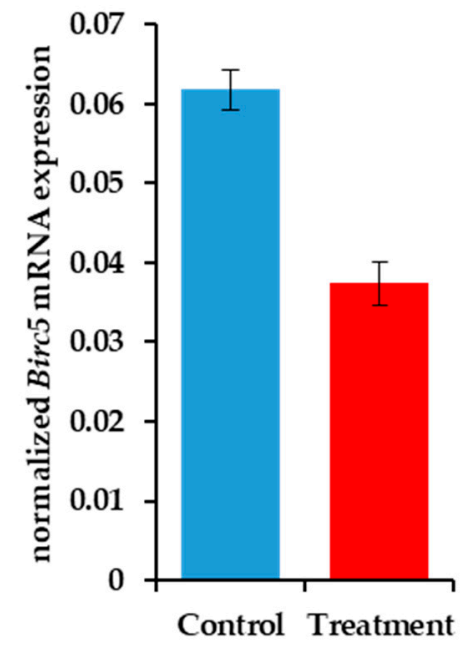

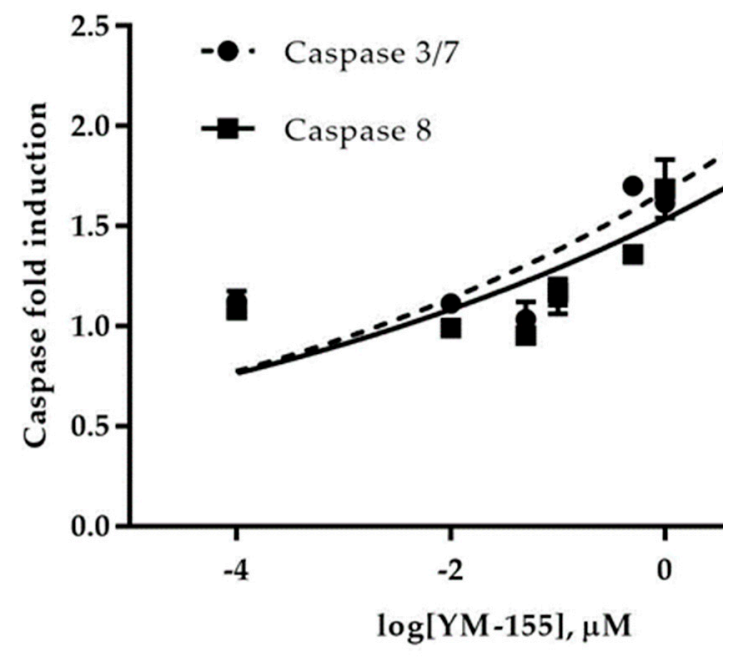

(b)

(c)

Figure 6. YM155 decreases viability and BIRC5 expression in HS-SY-II cells. (a) Cells were treated for $24 \mathrm{~h}$ with various concentrations of YM155 and then assayed for the conversion of MTT to formazan and correlated to cell viability. (b) Caspase $3 / 7$ \& 8 activity detection in response to YM155 treatment. Fold increases are normalized to control treated HS-SY-II cells. Error bars are SDM. (c) Normalized mean values for Birc5 expression. BIRC5 was normalized with GAPDH mRNA expression, bars represent the $\mathrm{SEM}, n=4(p=0.0006)$.

\subsection{Histone lysine Modifications Suggest an Epigenetic Mechanism of Action of YM155}

Using the HS-SY-II human synovial sarcoma cell line, we sought to delineate the epigenetic mechanisms surrounding the BIRC5 promoter in response to $0.2 \mu \mathrm{M}$ YM155 after $24 \mathrm{~h}$ of treatment. The YM155 dose is 10 -fold less than the $\mathrm{EC}_{50}$ measured for cell viability for $24 \mathrm{~h}$ so as to avoid globally induced artifacts of apoptosing cells. Cells were fractionated into nuclei with sonicated DNA in fragments that averaged $500 \mathrm{bp}$ in size. DNA was immunoprecipitated using rabbit polyclonal antibodies, and PCR was performed using primers that were specific for the promoter region of the BIRC5 gene. The treatment of HS-SY-II cells with YM155 resulted in an increase in enriched DNA in association with both H3K27 trimethylation and acetylation marks (Figure A3). We similarly performed PCR-chromatin immunoprecipitation on the mouse synovial sarcoma samples that were treated for 11 days with YM155. The concomitant enrichment for H3K27me3 and H3K27ac was also observed in these mouse synovial sarcomas (Figure 7a,b). Typically, we associate these signals as 
opposing one another, H3K27me3 leading to gene repression and H3K27ac leading to gene activation. We also studied the epigenetic mark, H3K4me1, and observed subtle decreases in the treated samples (Figure 7c). H3K4me1 is a modification that is context specific and can be associated with activated enhancer regions or synergistic repression when coupled with H3K27me3 [25-27]. While the mouse samples demonstrated a subtle decrease in H3K4me1 levels and the treated human cell lines exhibited a more dynamic decrease in enrichment (Figure A3). We next studied the levels of NFKB in response to YM155. NFKB is a putative transcription factor of the BIRC5 gene [28].

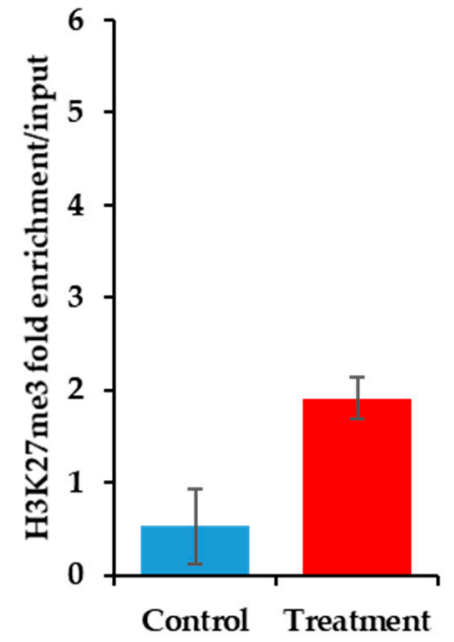

(a)

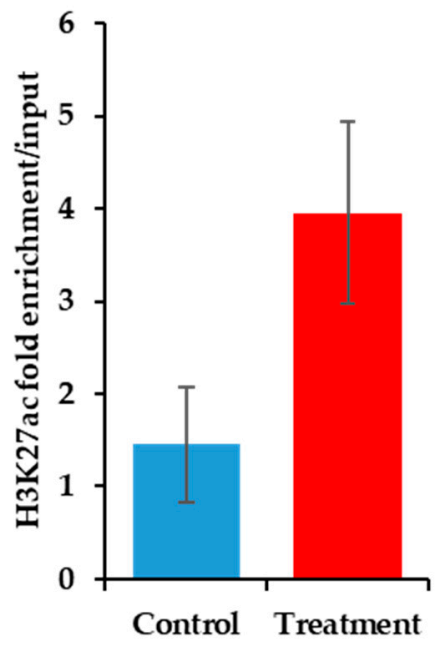

(b)

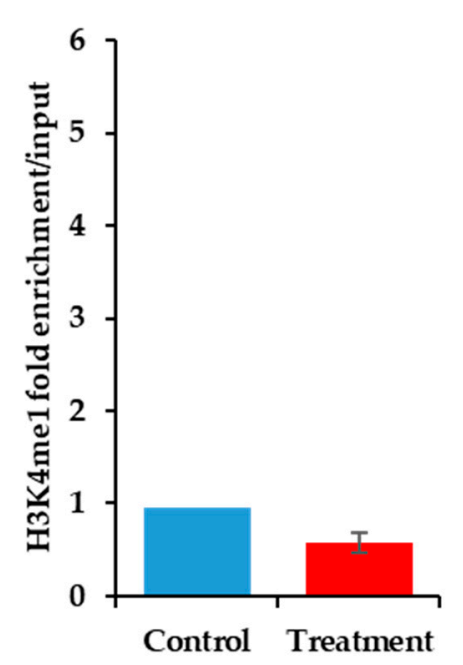

(c)

Figure 7. Epigenetic histone marks differ between control and YM155 treated mouse synovial sarcoma at the Birc5 promoter. (a) ChIP-qPCR for H3K27me3 shows elevated levels at the Birc5 promoter in the YM155 treated samples $(n=5)$ compared to controls $(n=3)$, error bars are SEM $(p=0.045)$. (b) ChIP-qPCR for H3K27ac shows elevated levels at the Birc5 promoter in the YM155 treated samples $(n=5)$ compared to controls $(n=3)$, error bars are SEM $(p=0.14)$. (c) ChIP-qPCR for H3K4me1 shows equally low levels at the Birc5 promoter between the YM155 treated samples $(n=5)$ compared to controls $(n=2)$, error bars for treated samples are SEM $(p=0.13)$.

\subsection{The Transcription Factor NFkB Increases upon YM155 Treatment, but Fails to Activate Birc5}

To determine the level of input in the epigenetic histone modifcations of the transcription factor $\mathrm{NF} \kappa \mathrm{B}$, we measured total protein levels and enrichment at the BIRC5 promoter. Protein was extracted from sarcomas involved in the animal study of YM155. A striking increase of NFkB was measured after immunoblotting in the YM155 treated sarcomas ( $p=0.015$, Student's $t$-test) (Figure 8a,b). Material to perform ChIP-qPCR on the mouse samples had been exhausted and thus we reverted back to the HS-SY-II cells treated for $24 \mathrm{~h}$ with $0.2 \mu \mathrm{M}$ YM155. We were unable to detect a difference in the binding of NFKB to the BIRC5 promoter in control and YM155 treated cells (Figure 8c). Therefore, despite the increase in survivin expression provided through a feedback loop mechanism, the repression of BIRC5 as evidenced by H3K27me3 ChIP-qPCR and decreased survivin expression results in an apoptotic phenotype (Figure 9). 


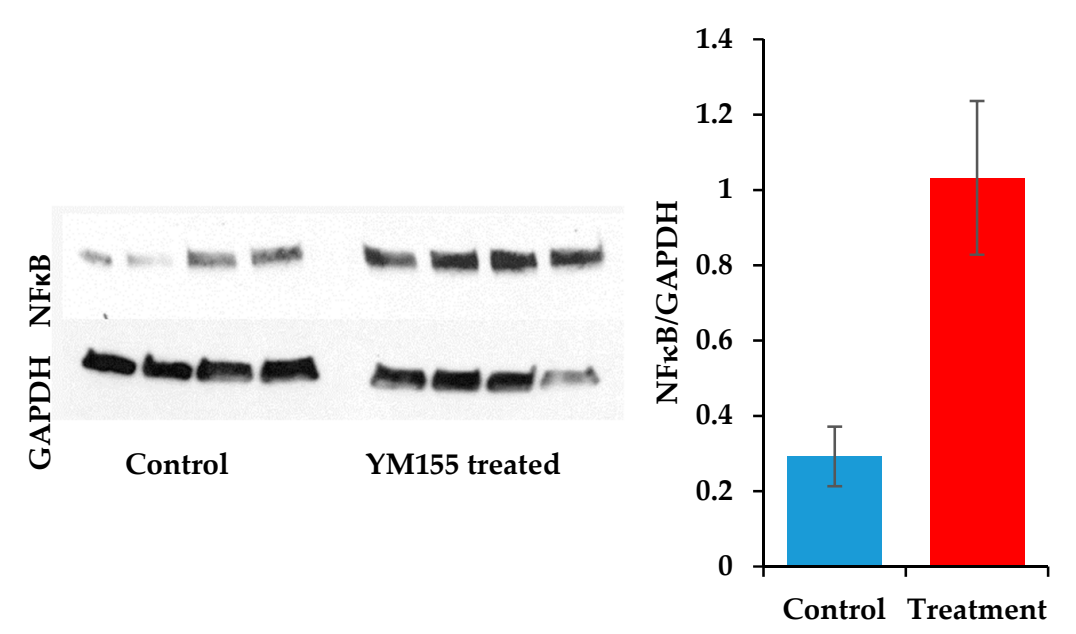

(a)

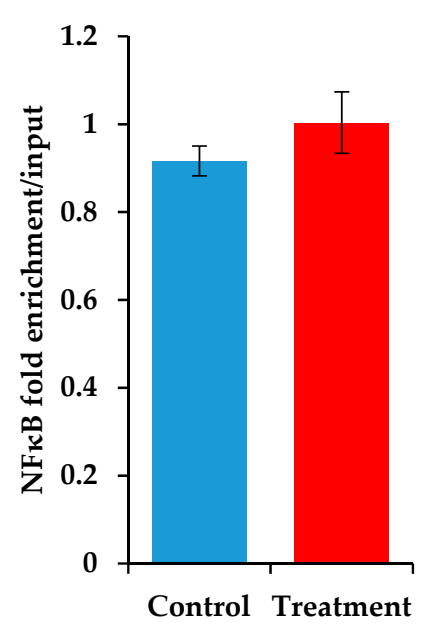

(c)

Figure 8. NFKB expression and Birc5 promoter binding in response to YM155. (a) Immunoblots of NFKB expression (top) and GAPDH (bottom) in control and YM155 treated mice after 11 days. (b) Quantification of band intensities of NFKB normalized to GAPDH expression, error bars for samples are SEM $(p=0.015)$. (c) ChIP-qPCR for NFKB demonstrates near equal levels at the Birc5 promoter between the YM155 treated HS-SY-II samples $(n=3)$ compared to controls $(n=3)$, error bars for treated samples are SEM $(p=0.32)$.

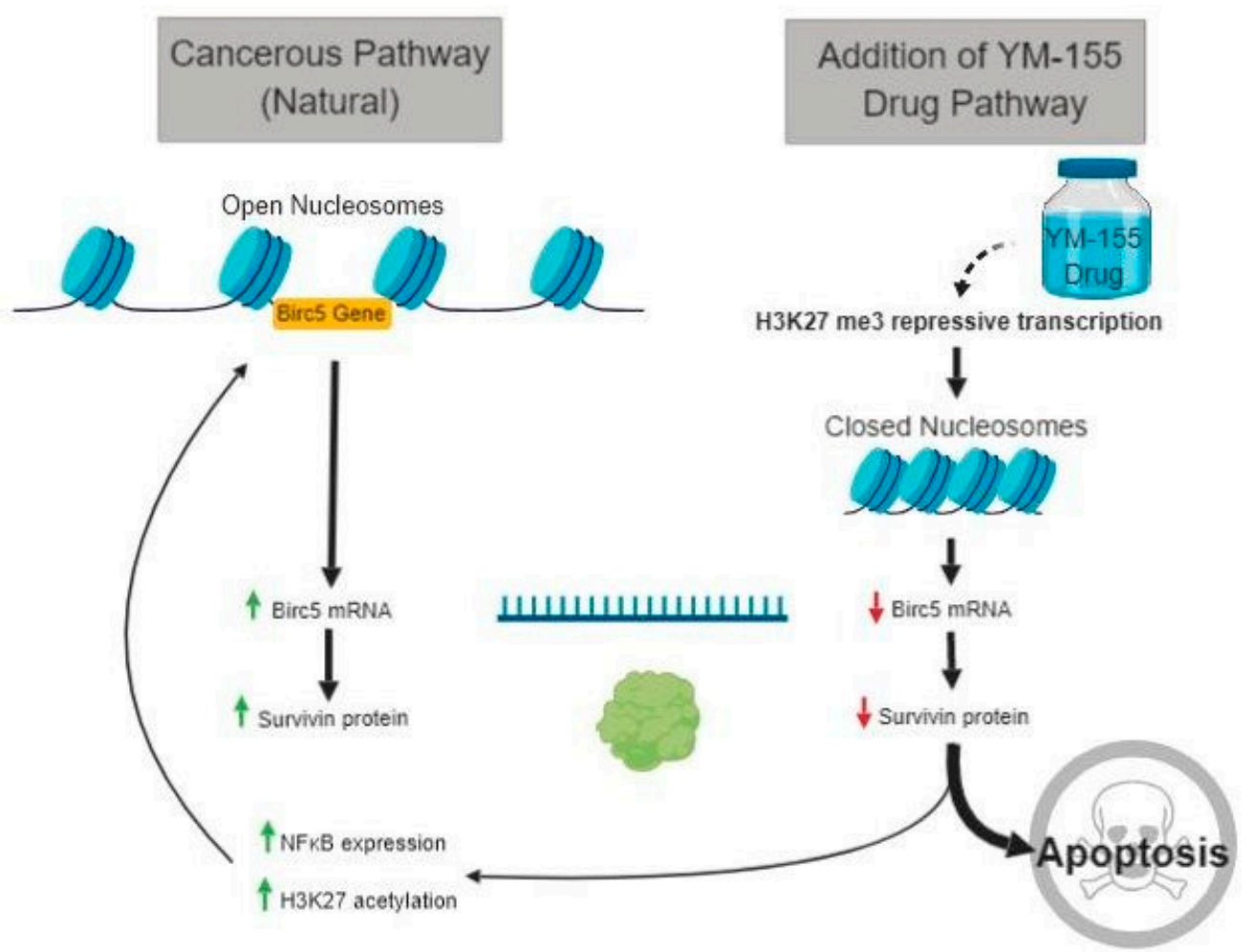

Figure 9. Survivin protein expression pathway in both control synovial sarcoma cells and YM155 treated synovial sarcoma cells.

\section{Discussion}

Survivin is a viable clinical target for the treatment of advanced cancers due to its overexpression in cancer compared to normal tissue. However, the current therapies to target survivin have unclear mechanisms of action most likely due to pleiotropic effects on other apoptosis-inducing pathways. 
Furthermore, the most studied inhibitor of survivin, YM155, is associated with serious adverse events without demonstrating increases in efficacy [22,23]. YM155 as a monotherapy is most likely not an option for clinical applications in treating synovial sarcoma. There is potential in treating synovial sarcoma and other survivin-expressing cancers with YM155 in combination with another targeted therapy. We have examined YM155 in combination with BCL2 inhibitors and found them to be minimally synergistic. Other studies are needed to find effective combinations. Additionally, more inhibitors of survivin are needed to dissociate the negative adverse events from the therapeutic benefits of targeting this protein in cancer.

In this study, we have demonstrated the potential indication utilizing YM155 in synovial sarcomas by applying YM155 to both in vitro and in vivo models of synovial sarcoma. The decrease in Birc5 and survivin expression, the induction of apoptosis, and the decrease in cell viability were clearly detected in synovial sarcoma upon YM155 exposure. However, less clear was the simultaneous enrichment of histone tail modifications at the BIRC5 promoter that traditionally are thought to promote repression (H3K27me3) or induce gene expression (H3K27ac).

This is not the first study to demonstrate concurrent increases in H3K27me3 and H3K27ac. In a study of hepatocarcinoma, other researchers observed through protein staining that both histone modification markers increased in a subset of samples and that elevated levels of these markers were associated with a poorer prognosis [29]. Increases of H3K27me3 and H3K27ac were not seen in the same nuclei of a cell, but in neighboring cells. Likewise, we are likely sampling two mixed populations of cells within our synovial sarcomas. While it would be parsimonious to assign the H3K27ac increase to non-cancerous cells in the tumor microenvironment, this study indicates that it is not solely non-cancerous that are responsible for the H3K27ac enrichment. However, we have previously measured the percentage of the population of cancerous cells and found it to be between $70 \%-95 \%$ in the non-metastatic models [20,30]. Further, normal tissue's contribution to the H3K27ac increase does not explain the H3K27ac increase observed in the in vitro experiments using HS-SY-II established cell lines.

Survivin has demonstrated biphasic expression upon constant exposure to apoptosis-inducing drugs in hepatocytes [28]. This biphasic expression is thought to be a result of the interconnections of survivin and cell cycle proteins that are specifically expressed during G2/M phase [31]. What we could be observing are cells in different phases of the cell cycle, which add additional regulation of the Birc5 gene. Despite the heterosynchronous state of the histone modifications, it is clear that apoptosis prevails. In response to decreased survivin expression, synovial sarcoma cells initiate feedback loops that increase expression of NFKB.

$N F K B$ is a transcription factor that is ubiquitously expressed throughout the body and is upregulated in cancer in response to receptor tyrosine kinases and other autocrine and paracrine signaling events [32]. Others have demonstrated that inhibition of NFKB using the compound BAY 11-7082 leads to a decrease in survivin levels [28]. We have demonstrated that NFkB is significantly upregulated in response to YM155 and that it loosely associates with the Birc5 promoter. The association of NFkB with the Birc5 promoter did not change in the presence of YM155. While YM155 could be interacting with $\mathrm{NFKB}$ to regulate survivin expression, another study demonstrated indirect effects of YM155 on ILF3/NF110 induced Birc5 expression [33]. The direct target of YM155 remains unproven, but the effects on epigenetic changes at the Birc5 promoter are evident in synovial sarcoma.

Knowing that epigenetic regulation of the Birc5 promoter is essential to YM155 activity, it would be interesting to test the combination of histone acetyltransferase (p300/CBP) inhibitors or demethylase (JMJD3) inhibitors with YM155 in the treatment of cancers listed in Table 1. The synergy of these approaches could overcome the concomitant expression of H3K27ac and H3K27me3 to predominantly favor repression of the Birc5 promoter, resulting in a more sensitive induction of apoptosis in cancer.

\section{Conclusions}

Synovial sarcoma is another survivin-expressing cancer and as such survivin can be a viable molecular target to treat patients with synovial sarcoma. However, the most widely used survivin 
inhibitor, YM155, exhibits adverse effects in patients and indirectly affects survivin/Birc5 levels through an ambiguous mechanism of action. We have demonstrated that histone modifications are altered in synovial sarcoma cells at the Birc5 promoter upon YM155 administration. Because YM155 exerts its effects through epigenetic regulation of the Birc5 promoter, administering YM155 in combination with histone acetyltransferase and DNA demethylase inhibitors might prove efficacious. However, without a precise mechanism of selectively targeting the Birc5 promoter with these epigenetic modifiers, a more productive approach may be to screen for novel survivin inhibitors with a more direct mechanism of action.

Author Contributions: Conceptualization, K.B.J. and J.J.B.; methodology, A.M., K.B.J., and J.J.B.; validation, A.M., S.E.L. and J.J.B..; formal analysis, A.M. and J.J.B.; investigation, A.M., S.E.L., A.P. A.L.H., and J.J.B.; resources, K.B.J. and J.J.B.; writing-Original draft preparation, A.M. and J.J.B.; writing-Review and editing, A.M., S.E.L. A.P., C.N., A.L.H., K.B.J., and J.J.B.; visualization, A.M., C.N. A.L.H., and J.J.B.; supervision, K.B.J. and J.J.B.; project administration, K.B.J. and J.J.B.; funding acquisition, K.B.J. and J.J.B.

Funding: This research was funded by the Paul Nabil Bustany Memorial Fund for Synovial Sarcoma Research, the National Cancer Institute (R01CA201396 and U54 CA231652), Alex's Lemonade Stand Foundation for Childhood Cancer, Idaho State University Career Path Internships, and Idaho State University Seed Grant.

Acknowledgments: The authors would like to acknowledge the assistance of Kyllie Smith-Fry in maintaining mouse colonies and supervising the care of animals during the course of treatment. Also we thank the Molecular Research Core Facility at Idaho State University for their assistance and equipment use for microscopy.

Conflicts of Interest: The authors declare no conflict of interest.

\section{Appendix A}

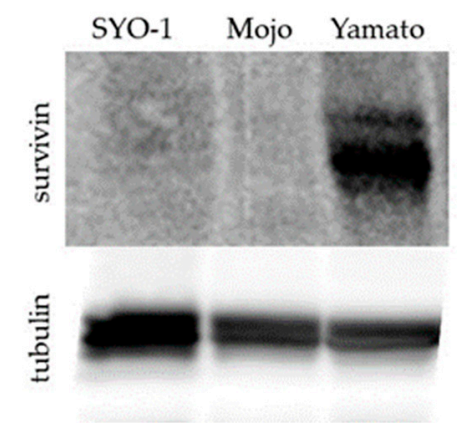

Figure A1. Immunoblot images of survivin and tubulin in human synovial sarcoma cell lines.

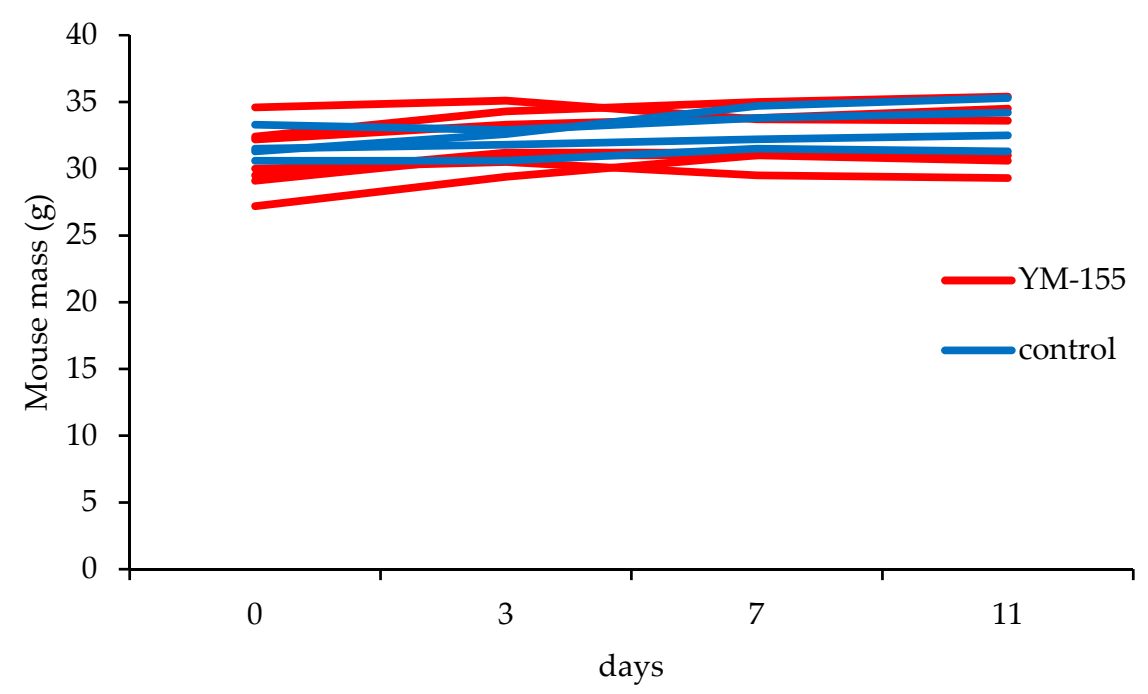

Figure A2. Weight changes in mice during the 11 days of YM155 treatment or control. No observable differences were seen for any individual mouse or between treatment groups. 


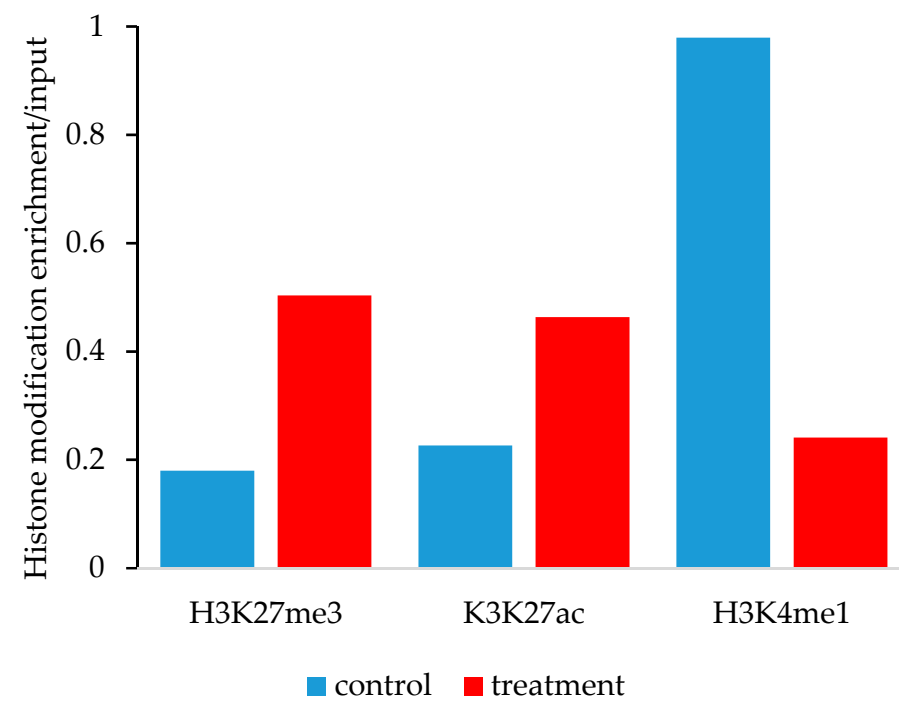

Figure A3. Epigenetic histone marks differ between control and YM155 treated human synovial sarcoma cells, HS-SY-II, at the BIRC5 promoter. ChIP-qPCR for H3K27me3 shows elevated levels at the BIRC5 promoter in the YM155 treated samples compared to controls. ChIP-qPCR for H3K27ac shows elevated levels at the BIRC5 promoter in the YM155 treated samples compared to controls. ChIP-qPCR for H3K4me1 shows a decrease at the BIRC5 promoter in the YM155 treated samples compared to controls.

\section{References}

1. Rajwanshi, A.; Srinivas, R.; Upasana, G. Malignant small round cell tumors. J. Cytol. 2009, 26, 1-10. [CrossRef] [PubMed]

2. Thway, K.; Fisher, C. Synovial sarcoma: Defining features and diagnostic evolution. Ann. Diagn. Pathol. 2014, 18, 369-380. [CrossRef]

3. Ladanyi, M. Fusions of the SYT and SSX genes in synovial sarcoma. Oncogene 2001, 20, 5755-5762. [CrossRef]

4. Kadoch, C.; Crabtree, G.R. Reversible disruption of mSWI/SNF (BAF) complexes by the SS18-SSX oncogenic fusion in synovial sarcoma. Cell 2013, 153, 71-85. [CrossRef]

5. Krieg, A.H.; Hefti, F.; Speth, B.M.; Jundt, G.; Guillou, L.; Exner, U.G.; von Hochstetter, A.R.; Cserhati, M.D.; Fuchs, B.; Mouhsine, E.; et al. Synovial sarcomas usually metastasize after $>5$ years: A multicenter retrospective analysis with minimum follow-up of 10 years for survivors. Ann. Oncol. 2011, 22, 458-467. [CrossRef]

6. Vlenterie, M.; Vlenterie, M.; Litière, S.; Rizzo, E.; Marréaud, S.; Judson, I.; Gelderblom, H.; Le Cesne, A.; Wardelmann, E.; Messiou, C.; et al. Outcome of chemotherapy in advanced synovial sarcoma patients: Review of 15 clinical trials from the European Organisation for Research and Treatment of Cancer Soft Tissue and Bone Sarcoma Group; setting a new landmark for studies in this entity. Eur. J. Cancer 2016, 58, 62-72. [CrossRef] [PubMed]

7. Eilber, F.C.; Brennan, M.F.; Eilber, F.R.; Eckardt, J.J.; Grobmyer, S.R.; Riedel, E.; Forscher, C.; Maki, R.G.; Singer, S. Chemotherapy is associated with improved survival in adult patients with primary extremity synovial sarcoma. Ann. Surg. 2007, 246, 105-113. [CrossRef]

8. Karavasilis, V.; Seddon, B.M.; Ashley, S.; Al-Muderis, O.; Fisher, C.; Judson, I. Significant clinical benefit of first-line palliative chemotherapy in advanced soft-tissue sarcoma: Retrospective analysis and identification of prognostic factors in 488 patients. Cancer 2008, 112, 1585-1591. [CrossRef]

9. Jaiswal, P.K.; Goel, A.; Mittal, R.D. Survivin: A molecular biomarker in cancer. Indian J. Med. Res. 2015, 141, 389-397.

10. Yamashita, S.; Masuda, Y.; Kurizaki, T.; Haga, Y.; Murayama, T.; Ikei, S.; Kamei, M.; Takeno, S.; Kawahara, K. Survivin expression predicts early recurrence in early-stage breast cancer. Anticancer Res. 2007, 27, 2803-2808. [PubMed] 
11. Taubert, H.; Heidenreich, C.; Holzhausen, H.J.; Schulz, A.; Bache, M.; Kappler, M.; Eckert, A.W.; Würl, P.; Melcher, I.; Hauptmann, K.; et al. Expression of survivin detected by immunohistochemistry in the cytoplasm and in the nucleus is associated with prognosis of leiomyosarcoma and synovial sarcoma patients. BMC Cancer 2010, 10, 65. [CrossRef]

12. Altieri, D.C. Survivin and IAP proteins in cell-death mechanisms. Biochem. J. 2010, 430, 199-205. [CrossRef] [PubMed]

13. Cheng, Q.; Ling, X.; Haller, A.; Nakahara, T.; Yamanaka, K.; Kita, A.; Koutoku, H.; Takeuchi, M.; Brattain, M.G.; Li, F. Suppression of survivin promoter activity by YM155 involves disruption of Sp1-DNA interaction in the survivin core promoter. Int. J. Biochem. Mol. Biol. 2012, 3, 179-197. [PubMed]

14. Yamauchi, T.; Nakamura, N.; Hiramoto, M.; Yuri, M.; Yokota, H.; Naitou, M.; Takeuchi, M.; Yamanaka, K.; Kita, A.; Nakahara, T.; et al. Sepantronium bromide (YM155) induces disruption of the ILF3/p54(nrb) complex, which is required for survivin expression. Biochem. Biophys. Res. Commun. 2012, 425, 711-716. [CrossRef] [PubMed]

15. Rauch, A.; Hennig, D.; Schäfer, C.; Wirth, M.; Marx, C.; Heinzel, T.; Schneider, G.; Krämer, O.H. Survivin and YM155: How faithful is the liaison? Biochim. Biophys. Acta 2014, 1845, 202-220. [CrossRef]

16. Tang, H.; Shao, H.; Yu, C.; Hou, J. Mcl-1 downregulation by YM155 contributes to its synergistic anti-tumor activities with ABT-263. Biochem. Pharmacol. 2011, 82, 1066-1072. [CrossRef] [PubMed]

17. Na, Y.S.; Yang, S.J.; Kim, S.M.; Jung, K.A.; Moon, J.H.; Shin, J.S.; Yoon, D.H.; Hong, Y.S.; Ryu, M.H.; Lee, J.L.; et al. YM155 induces EGFR suppression in pancreatic cancer cells. PLoS ONE 2012, 7, e38625. [CrossRef] [PubMed]

18. Lai, P.C.; Chen, S.H.; Yang, S.H.; Cheng, C.C.; Chiu, T.H.; Huang, Y.T. Novel survivin inhibitor YM155 elicits cytotoxicity in glioblastoma cell lines with normal or deficiency DNA-dependent protein kinase activity. Pediatr. Neonatol. 2012, 53, 199-204. [CrossRef]

19. Shaul, Y.D.; Yuan, B.; Thiru, P.; Nutter-Upham, A.; McCallum, S.; Lanzkron, C.; Bell, G.W.; Sabatini, D.M. MERAV: A tool for comparing gene expression across human tissues and cell types. Nucleic Acids Res. 2016, 44, D560-D566. [CrossRef]

20. Barrott, J.J.; Kafchinski, L.A.; Jin, H.; Potter, J.W.; Kannan, S.D.; Kennedy, R.; Mosbruger, T.; Wang, W.L.; Tsai, J.W.; Araujo, D.M.; et al. Modeling synovial sarcoma metastasis in the mouse: PI3'-lipid signaling and inflammation. J. Exp. Med. 2016, 213, 2989-3005. [CrossRef] [PubMed]

21. Barrott, J.J.; Illum, B.E.; Jin, H.; Zhu, J.F.; Mosbruger, T.; Monument, M.J.; Smith-Fry, K.; Cable, M.G.; Wang, Y.; Grossmann, A.H.; et al. beta-catenin stabilization enhances SS18-SSX2-driven synovial sarcomagenesis and blocks the mesenchymal to epithelial transition. Oncotarget 2015, 6, 22758-22766. [CrossRef] [PubMed]

22. Kelly, R.J.; Thomas, A.; Rajan, A.; Chun, G.; Lopez-Chavez, A.; Szabo, E.; Spencer, S.; Carter, C.A.; Guha, U.; Khozin, S.; et al. A phase I/II study of sepantronium bromide (YM155, survivin suppressor) with paclitaxel and carboplatin in patients with advanced non-small-cell lung cancer. Ann. Oncol. 2013, 24, 2601-2606. [CrossRef] [PubMed]

23. Clemens, M.R.; Gladkov, O.A.; Gartner, E.; Vladimirov, V.; Crown, J.; Steinberg, J.; Jie, F.; Keating, A. Phase II, multicenter, open-label, randomized study of YM155 plus docetaxel as first-line treatment in patients with HER2-negative metastatic breast cancer. Breast Cancer Res. Treat. 2015, 149, 171-179. [CrossRef]

24. Tolcher, A.W.; Mita, A.; Lewis, L.D.; Garrett, C.R.; Till, E.; Daud, A.I.; Patnaik, A.; Papadopoulos, K.; Takimoto, C.; Bartels, P.; et al. Phase I and pharmacokinetic study of YM155, a small-molecule inhibitor of survivin. J. Clin. Oncol. 2008, 26, 5198-5203. [CrossRef]

25. Heintzman, N.D.; Stuart, R.K.; Hon, G.; Fu, Y.; Ching, C.W.; Hawkins, R.D.; Barrera, L.O.; Van Calcar, S.; $\mathrm{Qu}, \mathrm{C} . ;$ Ching, K.A.; et al. Distinct and predictive chromatin signatures of transcriptional promoters and enhancers in the human genome. Nat. Genet. 2007, 39, 311-318. [CrossRef] [PubMed]

26. Blum, R.; Vethantham, V.; Bowman, C.; Rudnicki, M.; Dynlacht, B.D. Genome-wide identification of enhancers in skeletal muscle: The role of MyoD1. Genes Dev. 2012, 26, 2763-2779. [CrossRef]

27. Cheng, J.; Blum, R.; Bowman, C.; Hu, D.; Shilatifard, A.; Shen, S.; Dynlacht, B.D. A role for H3K4 monomethylation in gene repression and partitioning of chromatin readers. Mol. Cell 2014, 53, 979-992. [CrossRef]

28. Wang, K.; Brems, J.J.; Gamelli, R.L.; Holterman, A.X. Survivin signaling is regulated through nuclear factorkappa B pathway during glycochenodeoxycholate-induced hepatocyte apoptosis. Biochim. Biophys. Acta 2010, 1803, 1368-1375. [CrossRef] [PubMed] 
29. Hayashi, A.; Yamauchi, N.; Shibahara, J.; Kimura, H.; Morikawa, T.; Ishikawa, S.; Nagae, G.; Nishi, A.; Sakamoto, Y.; Kokudo, N.; et al. Concurrent activation of acetylation and tri-methylation of H3K27 in a subset of hepatocellular carcinoma with aggressive behavior. PLoS ONE 2014, 9, e91330. [CrossRef] [PubMed]

30. Jin, H.; Barrott, J.J.; Cable, M.G.; Monument, M.J.; Lerman, D.M.; Smith-Fry, K.; Nollner, D.; Jones, K.B. The Impact of Microenvironment on the Synovial Sarcoma Transcriptome. Cancer Microenviron. 2017, 10, 1-7. [CrossRef] [PubMed]

31. Deguchi, M.; Shiraki, K.; Inoue, H.; Okano, H.; Ito, T.; Yamanaka, T.; Sugimoto, K.; Sakai, T.; Ohmori, S.; Murata, K.; et al. Expression of survivin during liver regeneration. Biochem. Biophys. Res. Commun. 2002, 297, 59-64. [CrossRef]

32. Xia, Y.; Shen, S.; Verma, I.M. NF-kappaB, an active player in human cancers. Cancer Immunol. Res. 2014, 2, 823-830. [CrossRef] [PubMed]

33. Nakamura, N.; Yamauchi, T.; Hiramoto, M.; Yuri, M.; Naito, M.; Takeuchi, M.; Yamanaka, K.; Kita, A.; Nakahara, T.; Kinoyama, I.; et al. Interleukin enhancer-binding factor 3/NF110 is a target of YM155, a suppressant of survivin. Mol. Cell. Proteom. 2012, 11, M111.013243. [CrossRef] [PubMed]

(C) 2019 by the authors. Licensee MDPI, Basel, Switzerland. This article is an open access article distributed under the terms and conditions of the Creative Commons Attribution (CC BY) license (http:/ / creativecommons.org/licenses/by/4.0/). 